\title{
Saponified sunflower and safflower oils inhibit melanogenesis in B16 melanoma cells
}

\author{
JEUNG-HYUN KOO ${ }^{1}$, IKJAE LEE ${ }^{1}$, SEOK-KWEON YUN ${ }^{2}$, \\ HAN-UK KIM ${ }^{2}$, BYUNG-HYUN PARK ${ }^{1}$ and JIN-WOO PARK ${ }^{1}$ \\ Departments of ${ }^{1}$ Biochemistry, and ${ }^{2}$ Dermatology, Medical School and Diabetes Research Center, \\ Chonbuk National University, Jeonju, Jeonbuk 561-756, Korea
}

Received October 8, 2009; Accepted November 30, 2009

DOI: 10.3892/mmr_00000252

\begin{abstract}
The purpose of this study was to determine whether saponified sunflower and safflower oils can potentially be used as whitening agents, and to investigate their underlying mechanisms. Saponified sunflower (sap-SU) and safflower (sap-SA) oils dose-dependently inhibited isobutylmethylxanthine-induced melanogenesis in B16 melanoma cells, with no cytotoxicity. This decrease in melanin production was correlated with reduced enzyme activity and decreased mRNA and protein levels of tyrosinase. mRNA levels of microphthalmia-associated transcription factor and tyrosinase-related proteins 1 and 2 were also decreased by sap-SU and sap-SA, indicating the regulation of tyrosinase at the transcriptional level. Taken together, these results suggest that sap-SU and sap-SA can potentially be used as cosmetic whitening agents.
\end{abstract}

\section{Introduction}

Melanin is a unique pigmented biopolymer synthesized by melanocytes that exist in the dermal-epidermal border of the skin. Melanin production is an important defense mechanism against sunlight. However, excessive melanin production due to UV irradiation or chronic inflammation causes hyperpigmentation of the skin, resulting in melasma, lentigines, nevus, ephelis, freckles or age spots (1). The identification of an effective melanogenesis inhibitor is therefore of great interest both pharmaceutically and cosmetically.

The tyrosinase gene family plays a pivotal role in the regulation of melanogenesis (2). This family consists of tyrosinase, tyrosinase-related protein 1 (TRP-1) and

Correspondence to: Drs Jin-Woo Park and Byung-Hyun Park, Department of Biochemistry, Medical School and Diabetes Research Center, Chonbuk National University, Jeonju, Jeonbuk 561-756, Korea

E-mail: jinwoo@chonbuk.ac.kr; bhpark@chonbuk.ac.kr

Key words: saponification, sunflower oil, safflower oil, melanogenesis, B16 melanoma cells tyrosinase-related protein 2 (TRP-2) (1). Tyrosinase is a bifunctional enzyme that modulates melanin production, first by catalyzing the hydroxylation of tyrosine to DOPA, and secondly by catalyzing the oxidation of DOPA to DOPAquinone (3). TRP-2, which functions as a DOPAchrome tautomerase, catalyzes the rearrangement of DOPAchrome to 5,6-dihydroxyindole-2-carboxylic acid (4), and TRP-1 oxidizes dihydroxyindole-2-carboxylic acid to a carboxylated indole-quinone (5).

Though a number of whitening agents have been developed, they are often unsatisfactory due to unwanted side effects such as local irritation, contact dermatitis, ochronosis, atrophy and skin cancer (6). Thus, there is a need for safer but effective therapeutic agents. The use of natural products for this purpose has recently been the focus of much attention. For example, arbutin, which is obtained from the leaves of the bearberry plant, is known to inhibit tyrosinase activity (7). Kojic acid, a hydrophilic fungal derivative obtained from Aspergillus and Penicillium species, is the most popular agent employed in Asia for the treatment of melasma $(6,8)$. In addition, aleosin, licorice extract, ascorbic acid and soy proteins have been used to interrupt the process of melanogenesis (6). In addition, we recently reported that xanthohumol, scoparone and various herbal medicinal products have a potent inhibitory effect on melanogenesis in B16 melanoma cells (9-11). During screening for new melanogenesis inhibitors from natural sources, we found that the saponified products of sunflower oil (sap-SU) and safflower oil (sap-SA) were effective at inhibiting melanin production. In the present study, we investigated how these compounds inhibit isobutylmethylxanthine (IBMX)-induced melanogenesis in B16 melanoma cells.

\section{Materials and methods}

Cells and materials. The B16/F10 murine melanoma cell line was obtained from the Korean Cell Line Bank (Seoul, Korea). Cells were cultured in DMEM containing 10\% fetal bovine serum, $100 \mathrm{U} / \mathrm{ml}$ penicillin, $0.1 \mathrm{mg} / \mathrm{ml}$ streptomycin and $0.25 \mu \mathrm{g} / \mathrm{ml}$ amphotericin $\mathrm{B}$ at $37^{\circ} \mathrm{C}$ in a humidified $95 \%$ air $/ 5 \% \mathrm{CO}_{2}$ atmosphere. Sunflower oil (SU), safflower oil (SA) and IBMX were obtained from Sigma (St. Louis, MO, USA). Drug treatment began $24 \mathrm{~h}$ after seeding, and cells were harvested after two days of incubation. 
Table I. Gene accession numbers and primer sequences used in real-time RT-PCR.

\begin{tabular}{|c|c|c|}
\hline Gene & Primer sequences & Accession no. \\
\hline Tyrosinase & $\begin{array}{l}\text { Forward: TTGCCACTTCATGTCATCATAGAATATT } \\
\text { Reverse: TTTATCAAAGGTGTGACTGCTATACAAAT }\end{array}$ & NM011661 \\
\hline TRP-1 & $\begin{array}{l}\text { Forward: ATGCGGTCTTTGACGAATGG } \\
\text { Reverse: } \text { CGTTTTCCAACGGGAAGGT }\end{array}$ & NM031202 \\
\hline TRP-2 & $\begin{array}{l}\text { Forward: CTCAGAGCTCGGGCTCAGTT } \\
\text { Reverse: TGTTCAGCACGCCATCCA }\end{array}$ & X63349 \\
\hline MITF & $\begin{array}{l}\text { Forward: CGCCTGATCTGGTGAATCG } \\
\text { Reverse: CCTGGCTGCAGTTCTCAAGAA }\end{array}$ & NM008601 \\
\hline GAPDH & $\begin{array}{l}\text { Forward: CGTCCCGTAGACAAAATGGT } \\
\text { Reverse: TTGATGGCAACAATCTCCAC }\end{array}$ & NM008084 \\
\hline
\end{tabular}

TRP-1 and -2, tyrosine-related protein 1 and 2; MITF, microphthalmia-associated transcription factor.

Saponification of sunflower and safflower oils. SU or SA (1 g) was mixed with $1 \mathrm{ml} 2.5 \mathrm{~N} \mathrm{KOH}$ in ethanol, and saponification was conducted at $80^{\circ} \mathrm{C}$ for $30 \mathrm{~min}$. After saponification, the $\mathrm{pH}$ of the solution was adjusted to 7.4.

MTT assay. The viability of cultured cells was determined by reduction of 3-(4,5-dimethylthiazol-2-yl)-2,5-diphenyltetrazolium bromide (MTT) to formazan. Cells were seeded in 96-well plates and cultured for $24 \mathrm{~h}$. After drug treatment, MTT $(5 \mathrm{mg} / \mathrm{ml}$ in PBS, $100 \mu \mathrm{l})$ was added to each well. Cells were incubated at $37^{\circ} \mathrm{C}$ for $30 \mathrm{~min}$ and dimethyl sulfoxide $(100 \mu \mathrm{l})$ was added to dissolve the formazan crystals. Absorbance was measured at $570 \mathrm{~nm}$ with a spectrophotometer (Spectra Max Plus; Molecular Devices, Sunnyvale, CA, USA).

Measurement of melanin content. The melanin content of the cultured B16 cells was measured as described previously (11). Briefly, the cells were washed twice with PBS and lysed with $20 \mathrm{mM}$ Tris-0.1\% Triton X-100 (pH 7.5). Cell lysates were precipitated with the same amount of $20 \%$ trichloroacetic acid. After washing twice with $10 \%$ trichloroacetic acid, the pellets were treated with ethyl alcohol:diethyl ether (3:1) and diethyl ether, successively. Samples were air-dried, dissolved in $1 \mathrm{ml} 0.85 \mathrm{M} \mathrm{KOH}$ and boiled for $15 \mathrm{~min}$. After cooling, the absorbance was measured with a spectrophotometer at $440 \mathrm{~nm}$. The amount of cellular melanin was corrected according to the protein content of the samples, which was determined using Bradford's assay (12).

Tyrosinase activity assay. Tyrosinase activity was assayed as DOPA oxidase activity (13), with some modifications. The cell lysate was obtained after washing the cells twice with PBS. Tyrosinase activity was analyzed spectrophotometrically by following the oxidation of DOPA to DOPAchrome at $475 \mathrm{~nm}$. The reaction mixture containing $100 \mu \mathrm{l}$ of freshly prepared substrate solution $(0.1 \% \mathrm{~L}-\mathrm{DOPA}$ in $0.1 \mathrm{M}$ sodium phosphate, $\mathrm{pH}$ 6.0) and $50 \mu 1$ of enzyme solution was incubated at $37^{\circ} \mathrm{C}$. The change in absorbance was measured during the first 10 min of the reaction, while the increase in absorbance was linear, and corrections for the auto-oxidation of L-DOPA in the controls were carried out. Tyrosinase activity was corrected according to the protein content of the samples, and is presented as a percentage relative to the IBMX-treated control cells.

Western blotting. Cells were homogenized in ice-cold lysis buffer. Homogenates containing $10 \mu \mathrm{g}$ of protein were separated by SDS-PAGE with a $10 \%$ resolving and $3 \%$ acrylamide stacking gel and transferred to a nitrocellulose membrane in a Western blot apparatus run at $100 \mathrm{~V}$ for $1.5 \mathrm{~h}$. The nitrocellulose membrane was blocked with $2 \%$ bovine serum albumin and then incubated overnight with $1 \mu \mathrm{g} / \mathrm{ml}$ goat anti-murine tyrosinase IgG (Santa Cruz Biochemicals, Santa Cruz, CA, USA). The binding of the antibody was detected with anti-goat IgG conjugated to horseradish peroxidase (Sigma). Immunoblots were developed using an Enhanced Chemiluminescence Plus kit (Amersham Biosciences, Buckinghamshire, UK).

RNA isolation and real-time RT-PCR. Total cellular RNA was prepared using TRIzol solution (Invitrogen, Paisley, UK) according to the manufacturer's instructions. RNA was then precipitated with isopropanol and dissolved in diethylpyrocarbonate-treated distilled water. First-strand cDNA was generated with the oligo dT-adaptor primers by reverse transcriptase (Takara, Japan). Specific primers (Table I) were designed using Primer Express software (Applied Biosystems, Foster City, CA, USA). GAPDH was used as the invariant control. The real-time PCR reaction $(10 \mu \mathrm{l})$ contained $10 \mathrm{ng}$ of reverse-transcribed RNA, $200 \mathrm{nM}$ each of forward and reverse primers, and a PCR master mixture. The reaction was performed in 384-well plates using the ABI PRISM 7900HT Sequence Detection System (Applied Biosystems). All reactions were conducted in triplicate.

Statistical analysis. Data were statistically analyzed using ANOVA and the Newman-Keuls test. Differences of $p<0.05$ were considered statistically significant. 
A
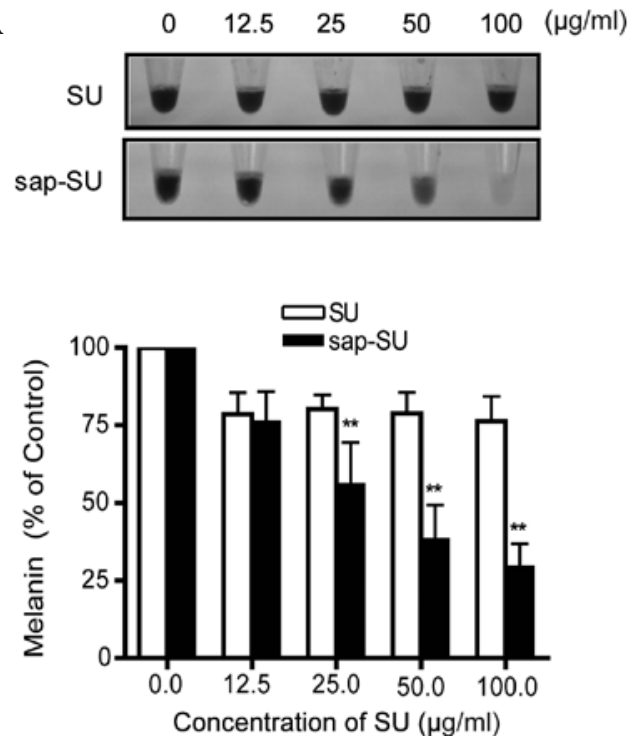

B
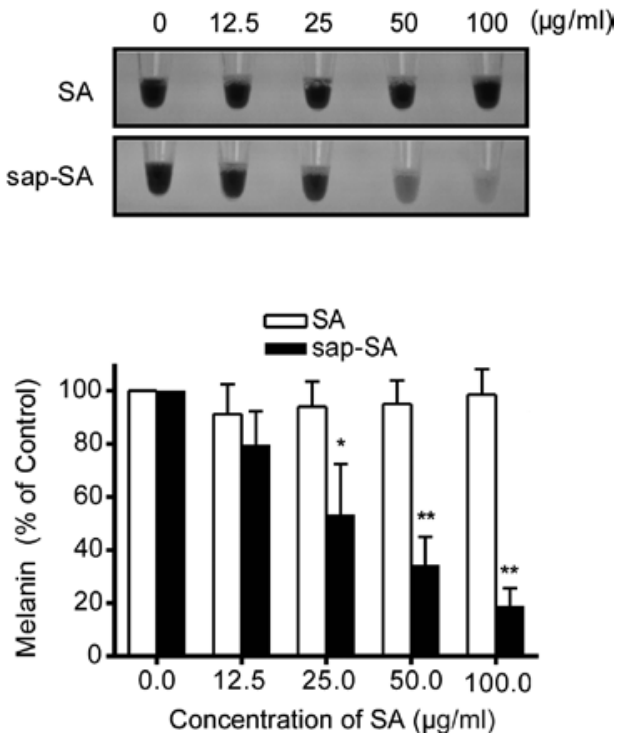

Figure 1. Effect of saponified oils on the melanin content of B16 melanoma cells. B16 cells (5x106 cells/well) were incubated with the indicated concentrations of (A) sunflower oil (SU) or saponified SU (sap-SU), or (B) safflower oil (SA) or saponified SA (sap-SA) in the presence of 0.1 mM isobutylmethylxanthine (IBMX) for two days. Melanin and protein content were determined as described in Materials and methods. Data are expressed as a percentage of the IBMXtreated controls and are presented as the mean \pm SEM of three separate experiments. ${ }^{*} \mathrm{P}<0.05$ and ${ }^{* *} \mathrm{P}<0.01$ vs. the IBMX-treated control.

\section{Results}

Inhibition of melanin synthesis by sap-SU and sap-SA. When B16 cells were incubated with IBMX, the cell suspension turned black, indicating increased cellular melanogenesis. SU and SA themselves did not affect melanin production by B16 cells, while sap-SU and sap-SA dose-dependently decreased the IBMX-induced black color (Fig. 1). Quantification of the melanin content revealed that $25 \mu \mathrm{g} / \mathrm{ml}$ of sap-SU (Fig. 1A) and of sap-SA (Fig. 1B) inhibited melanin production significantly. Cell viability as determined by the MTT assay was not affected by sap-SU or sap-SA at any of the concentrations tested (data not shown). Even at sap-SU or sap-SA concentrations of $100 \mu \mathrm{g} / \mathrm{ml}$, cells were still viable, while the cellular melanin content decreased to $29.6 \pm 7.2$ or $18.9 \pm 6.7 \%$ of the controls, respectively.

Inhibition of tyrosinase activity by sap-SU and sap-SA. Saponified SU and SA dose-dependently decreased cellular tyrosinase activity (Fig. 2), the rate-limiting step in melanin biosynthesis, in parallel with a decrease in melanin content (Fig. 1). However, the presence of sap-SU or sap-SA in the reaction mixture did not affect tyrosinase activity (data not shown), indicating that the decrease in tyrosinase activity by sap-SU and sap-SA was not due to the direct inhibition of tyrosinase activity.

Down-regulation of the expression of tyrosinase and related genes by sap-SU and sap-SA. To determine the tyrosinase expression levels of cells treated with sap-SU or sap-SA, Western blotting and real-time PCR analysis were performed. IBMX treatment increased tyrosinase protein expression. This induction was dose-dependently inhibited by sap-SU and sap-SA (Fig. 3). Saponified SU and SA also decreased IBMX-induced tyrosinase mRNA levels (Fig. 4). These results indicate that sap-SU and sap-SA inhibit tyrosinase

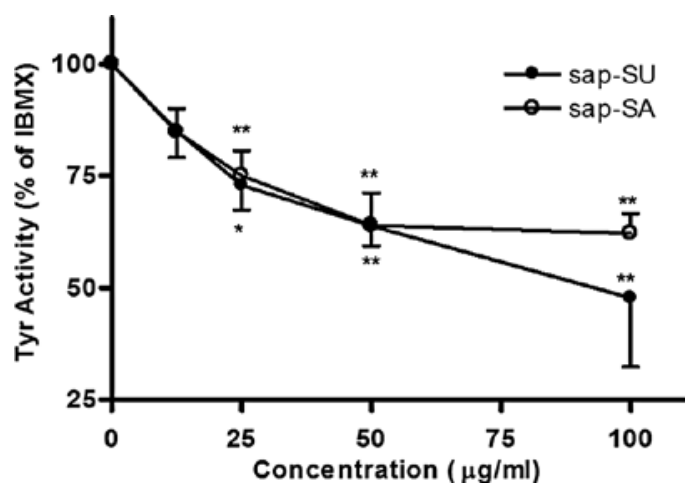

Figure 2. Effect of saponified oils on cellular tyrosinase activity. B16 cells $\left(5 \times 10^{6}\right.$ cells/well $)$ were treated with the indicated concentrations of sap-SU or sap-SA in the presence of $0.1 \mathrm{mM}$ IBMX for two days. Tyrosinase activity in the cellular lysates was determined as described in Materials and methods. Data are expressed as a percentage of the IBMX-treated controls and are presented as the mean \pm SEM of three separate experiments. ${ }^{*} \mathrm{P}<0.05$ and ${ }^{* *} \mathrm{P}<0.01$ vs. the IBMX-treated control.

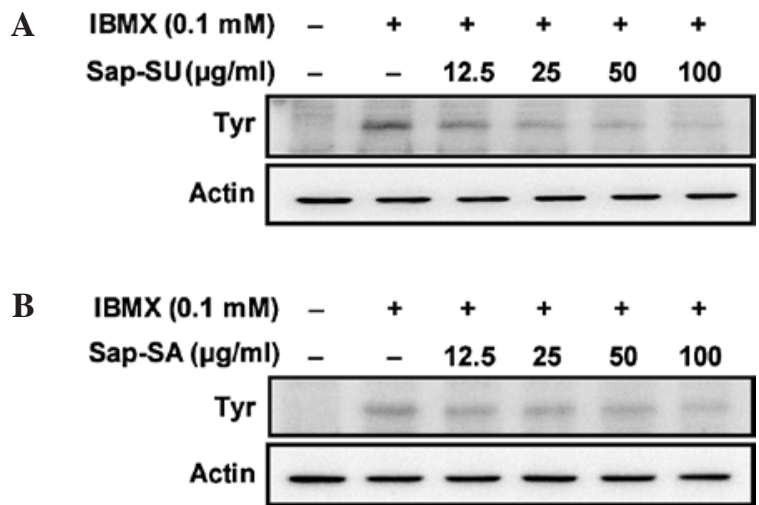

Figure 3. Effect of saponified oils on tyrosinase protein expression. B16 cells $\left(5 \times 10^{6}\right.$ cells/well) were treated with the indicated concentrations of (A) sap-SU or (B) sap-SA in the presence or absence of $0.1 \mathrm{mM}$ IBMX for two days. Tyrosinase protein was analyzed by Western blotting. Experiments were performed three times with similar results, and a typical trial is presented. 

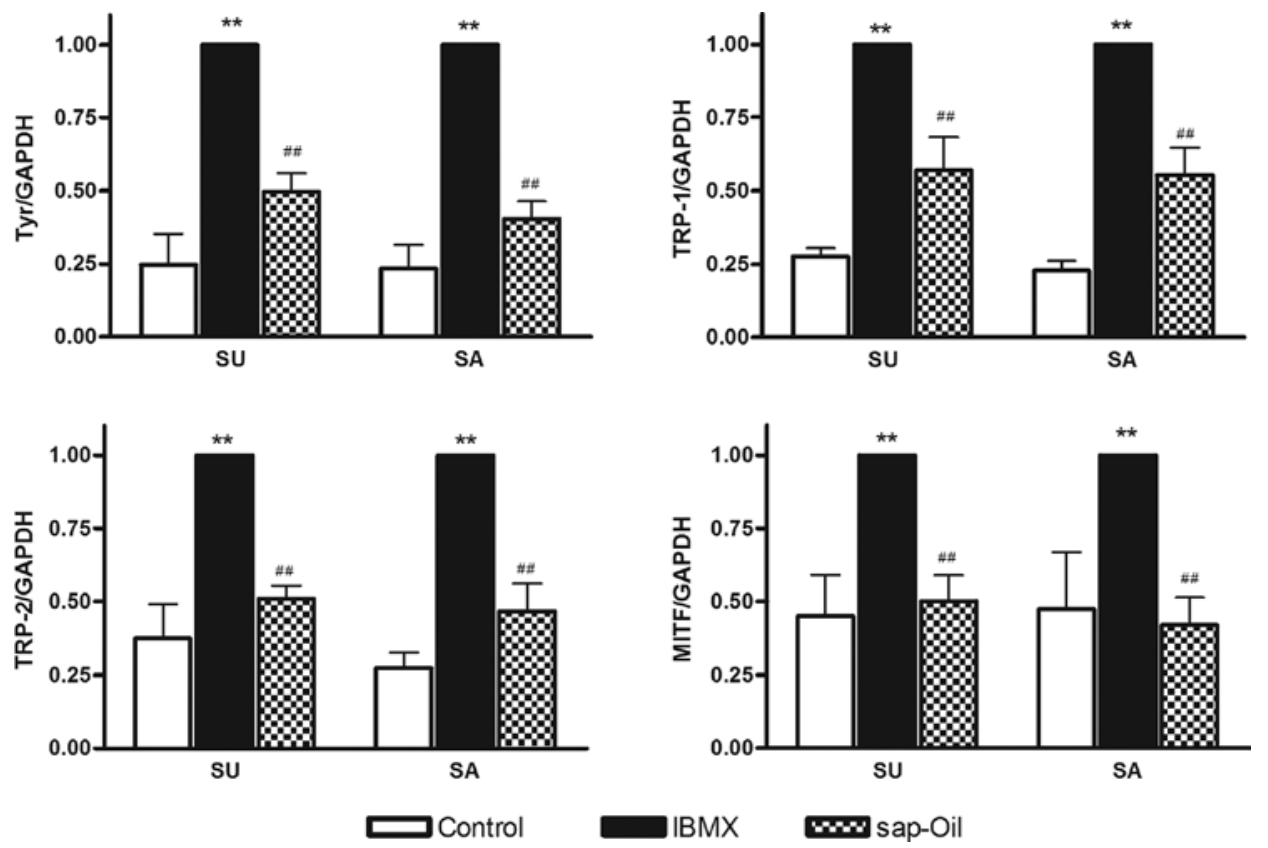

Figure 4. Effect of saponified oils on the mRNA expression of melanogenesis-related genes: tyrosine (Tyr), tyrosine-related protein 1 and 2 (TRP-1 and -2) and microphthalmia-associated transcription factor (MITF). B16 cells $\left(5 \times 10^{6}\right.$ cells/well) were treated with $0.1 \mathrm{mM}$ IBMX for two days in the presence or absence of $50 \mu \mathrm{g} / \mathrm{ml}$ of sap-SU or sap-SA. Total RNA was extracted, and mRNA expression was analyzed by real-time RT-PCR. Data are expressed as the mean \pm SEM of three separate experiments. ${ }^{* *} \mathrm{P}<0.01$ vs. control; ${ }^{* \# P}<0.01$ vs. IBMX.

at the transcriptional level. Furthermore, saponified SU and SA decreased the mRNA expression of TRP-1, TRP-2 and microphthalmia-associated transcription factor (MITF) (Fig. 4).

\section{Discussion}

To investigate whether it is possible to use the saponified products of SU and SA as whitening cosmetic agents, we evaluated whether these compounds inhibit melanogenesis in IBMX-treated B16 melanoma cells. IBMX increases cellular cAMP by inhibiting the cAMP-degrading enzyme, phosphodiesterase (14). Protein kinase A (PKA) phosphorylates and activates the cAMP response element binding protein that binds to the cAMP response element in the $\mathrm{M}$ promoter of the MITF gene $(15,16)$. In humans, mutations affecting the MITF pathway lead to pigmentary and auditory defects that are known collectively as Waardenburg syndrome (17). The increase in MITF-M expression induces the up-regulation of members of the tyrosinase gene family, resulting in increased melanin synthesis $(17,18)$. We showed in this study that saponified SU and SA blocked the IBMX-induced increase in melanogenesis and significantly decreased the expression of MITF mRNA. The decrease in the expression level of MITF mRNA was mirrored by decreases in the expression levels of tyrosinase, TRP-1 and TRP-2 mRNA. These results suggest that sap-SU and sap-SA inhibit the melanogenesis process at the transcriptional level.

To determine the mechanisms underlying the anti-melanogenic effects of sap-SU and sap-SA, the compositions of SU and SA were compared. SU is composed of palmitic acid $(6.4 \%)$, stearic acid $(1.3 \%)$, arachidic acid $(4.0 \%)$, behenic acid $(0.8 \%)$, oleic acid $(21.3 \%)$, linoleic acid $(66.2 \%)$ and linolenic acid $(<0.1 \%)$ (19). Safflower oil has a similar composition: palmitic acid $(6.4 \%)$, stearic acid $(3.1 \%)$, arachidic acid (1.2\%), oleic acid (13.4\%), linoleic acid (76.6-79\%) and linolenic acid (0.04-0.13\%) (19). Linoleic acid is the predominant fatty acid in both SU and SA. It has been reported that unsaturated fatty acids such as oleic acid, linoleic acid and linolenic acid decrease melanin synthesis and tyrosinase activity, while saturated fatty acids such as palmitic acid and stearic acid increase melanogenesis $(20,21)$. Thus, the high proportions of linoleic acid in SA and SU may underlie the anti-melanogenic effects of these oils.

Elucidating the molecular mechanisms underlying hyperpigmentation could lead to the development of technology that allows for the removal of unwanted pigmentation, the treatment of photoaging, and the design of tanning products with the potential to reduce the risk of skin cancer. Our findings that sap-SU and sap-SA are highly effective at inhibiting melanogenesis is of great importance, since SU and SA are already components of the human diet and are therefore likely to be relatively safe when used in the long-term. In conclusion, we demonstrated that sap-SU and sap-SA inhibit IBMX-induced melanogenesis by suppressing the expression of tyrosinase and related enzymes, and suggest that this effect may be related to the high proportions of linoleic acid present in SU and SA. Sap-SU and sap-SA therefore may be effective and safe hypo-pigmenting agents.

\section{Acknowledgements}

This study was supported by a grant from the Ministry of Science and Technology (MoST)/Korea Science and Engineering Foundation (KOSEF) through the Diabetes Research Center at Chonbuk National University (R13-2008-005-0000-0). 


\section{References}

1. Hearing VJ: Regulation of melanin formation. In: The Pigmentary System: Physiology and Pathophysiology. Nordlund JJ, Boissy RE, Hearing VJ, King RA and Ortonne J-P (eds). Oxford University Press, Inc., New York, pp423-438, 1998.

2. Pawelek JM and Chakraborty AK: The enzymology of melanogenesis. In: The Pigmentary System: Physiology and Pathophysiology. Nordlund JJ, Boissy RE, Hearing VJ, King RA and Ortonne J-P (eds). Oxford University Press, Inc., New York, pp391-400, 1998.

3. Hearing VJ and Jimenez M: Mammalian tyrosinase - the critical regulatory control point in melanocyte pigmentation. Int J Biochem 19: 1141-1147, 1987.

4. Yokoyama K, Yasumoto K, Suzuki H and Shibahara S: Cloning of the human DOPAchrome tautomerase/tyrosinase-related protein 2 gene and identification of two regulatory regions required for its pigment cell-specific expression. J Biol Chem 269: 27080-27087, 1994

5. Kobayashi T, Urabe K, Winder A, Jimenez-Cervantes C Imokawa G, Brewington T, Solano F, Garcia-Borron JC and Hearing VJ: Tyrosinase related protein 1 (TRP1) functions as a DHICA oxidase in melanin biosynthesis. EMBO J 13: 5818-5825, 1994.

6. Draelos ZD: Skin lightening preparations and the hydroquinone controversy. Dermatol Ther 20: 308-313, 2007.

7. Maeda K and Fukuda M: Arbutin: mechanism of its depigmenting action in human melanocyte culture. J Pharmacol Exp Ther 276 : 765-769, 1996.

8. Lim JT: Treatment of melasma using kojic acid in a gel containing hydroquinone and glycolic acid. Dermatol Surg 25: 282-284, 1999.

9. Koo JH, Kim HT, Yoon HY, Kwon KB, Choi IW, Jung SH, Kim HU, Park BH and Park JW: Effect of xanthohumol on melanogenesis in B16 melanoma cells. Exp Mol Med 40: 313-319, 2008
10. Lv N, Koo JH, Yoon HY, Yu J, Kim KA, Choi IW, Kwon KB, Kwon KS, Kim HU, Park JW and Park BH: Effect of Angelica gigas extract on melanogenesis in B16 melanoma cells. Int J Mol Med 20: 763-767, 2007.

11. Yang JY, Koo JH, Song YG, Kwon KB, Lee JH, Sohn HS, Park BH, Jhee EC and Park JW: Stimulation of melanogenesis by scoparone in B16 melanoma cells. Acta Pharmacol Sin 27: 1467-1473, 2006

12. Bradford MM: A rapid and sensitive method for the quantitation of microgram quantities of protein utilizing the principle of protein-dye binding. Anal Biochem 72: 248-254, 1976.

13. Lerch K: Monophenol monooxygenase from Neurospora crassa. Methods Enzymol 142: 165-169, 1987.

14. Beavo JA, Rogers NL, Crofford OB, Hardman JG, Sutherland EW and Newman EV: Effects of xanthine derivatives on lipolysis and on adenosine 3',5'-monophosphate phosphodiesterase activity. Mol Pharmacol 6: 597-603, 1970.

15. Levy C, Khaled M and Fisher DE: MITF: master regulator of melanocyte development and melanoma oncogene. Trends Mol Med 12: 406-414, 2006.

16. Tachibana M: MITF: a stream flowing for pigment cells. Pigment Cell Res 13: 230-240, 2000.

17. Lin JY and Fisher DE: Melanocyte biology and skin pigmentation. Nature 445: 843-850, 2007.

18. Busca R and Ballotti R: Cyclic AMP a key messenger in the regulation of skin pigmentation. Pigment Cell Res 13: 60-69, 2000

19. Budavari S, O'Neil MJ, Smith A, Heckelman PE and Kinneary JF: The Merck Index. 12th edition. Merck \& Co., Inc., Whitehouse Station, NJ, 1996.

20. Ando H, Funasaka Y, Oka M, Ohashi A, Furumura M, Matsunaga J, Matsunaga N, Hearing VJ and Ichihashi M: Possible involvement of proteolytic degradation of tyrosinase in the regulatory effect of fatty acids on melanogenesis. J Lipid Res 40: 1312-1316, 1999.

21. Ando H, Ryu A, Hashimoto A, Oka M and Ichihashi M: Linoleic acid and alpha-linolenic acid lightens ultraviolet-induced hyperpigmentation of the skin. Arch Dermatol Res 290: 375-381, 1998. 